

\section{NOTICE}

The submitted manuscript has been offered by an employee of the Alliance for Sustainable Energy, LLC (ASE), a contractor of the US Government under Contract No. DE-AC36-08-GO28308. Accordingly, the US Government and ASE retain a nonexclusive royalty-free license to publish or reproduce the published form of this contribution, or allow others to do so, for US Government purposes.

This report was prepared as an account of work sponsored by an agency of the United States government. Neither the United States government nor any agency thereof, nor any of their employees, makes any warranty, express or implied, or assumes any legal liability or responsibility for the accuracy, completeness, or usefulness of any information, apparatus, product, or process disclosed, or represents that its use would not infringe privately owned rights. Reference herein to any specific commercial product, process, or service by trade name, trademark, manufacturer, or otherwise does not necessarily constitute or imply its endorsement, recommendation, or favoring by the United States government or any agency thereof. The views and opinions of authors expressed herein do not necessarily state or reflect those of the United States government or any agency thereof.

Available electronically at http://www.osti.gov/bridge

Available for a processing fee to U.S. Department of Energy and its contractors, in paper, from:

U.S. Department of Energy

Office of Scientific and Technical Information

P.O. Box 62

Oak Ridge, TN 37831-0062

phone: 865.576.8401

fax: 865.576 .5728

email: mailto:reports@adonis.osti.gov

Available for sale to the public, in paper, from:

U.S. Department of Commerce

National Technical Information Service

5285 Port Royal Road

Springfield, VA 22161

phone: 800.553.6847

fax: 703.605.6900

email: orders@ntis.fedworld.gov

online ordering: http://www.ntis.gov/ordering.htm 


\title{
Integrated Vehicle Thermal Management for Advanced Vehicle Propulsion Technologies
}

\author{
Kevin Bennion, Matthew Thornton \\ National Renewable Energy Laboratory, Center for Transportation Technologies and Systems, USA
}

\begin{abstract}
A critical element to the success of new propulsion technologies that enable reductions in fuel use is the integration of component thermal management technologies within a viable vehicle package. Vehicle operation requires vehicle thermal management systems capable of balancing the needs of multiple vehicle systems that may require heat for operation, require cooling to reject heat, or require operation within specified temperature ranges. As vehicle propulsion transitions away from a single form of vehicle propulsion based solely on conventional internal combustion engines (ICEs) toward a wider array of choices including more electrically dominant systems such as plug-in hybrid electric vehicles (PHEVs), new challenges arise associated with vehicle thermal management. As the number of components that require active thermal management increase, so do the costs in terms of dollars, weight, and size. Integrated vehicle thermal management is one pathway to address the cost, weight, and size challenges. The integration of the power electronics and electric machine (PEEM) thermal management with other existing vehicle systems is one path for reducing the cost of electric drive systems. This work demonstrates techniques for evaluating and quantifying the integrated transient and continuous heat loads of combined systems incorporating electric drive systems that operate primarily under transient duty cycles, but the approach can be extended to include additional steady-state duty cycles typical for designing vehicle thermal management systems of conventional vehicles. The work compares opportunities to create an integrated low temperature coolant loop combining the power electronics and electric machine with the air conditioning system in contrast to a high temperature system integrated with the ICE cooling system.
\end{abstract}

\section{INTRODUCTION}

Vehicle thermal management systems are critical in terms of safety, reliability, performance, and passenger comfort. The application of thermal management technologies to vehicle propulsion technologies dominated by conventional internal combustion engines (ICEs) developed gradually over approximately the last hundred years, as shown by a patent in 1919 related to engine cooling [1]. Changes in vehicle propulsion configurations away from systems dominated by ICEs and toward more electrically dominant systems with electric drives will affect the potential heat load balance within a vehicle and require new techniques to meet the multiple demands placed on vehicle thermal management systems.

Since they were first introduced in the United States in 1999, interest in hybrid electric vehicles (HEVs) has grown. The development of HEVs promoted the development of critical electric drive technologies applicable not only to HEVs but also to other advanced vehicle technologies incorporating electric drive systems. Examples include plug-in hybrid electric vehicles (PHEVs), electric vehicles (EVs), and fuel cell vehicles

Page 1 of 15 
(FCVs). The adoption of electric drive systems brings additional thermal management requirements associated with energy storage, power electronics, and electric machines that can experience significant transient thermal loading. In addition to these new requirements, the conventional methods for vehicle thermal management are impacted by the transition to alternate propulsion systems less dependent on continuous operation of an ICE.

The additional thermal management requirements associated with electric drive systems are a recognized challenge in terms of costs related to the thermal management hardware, not only in terms of dollars but also in weight and size that impact the overall vehicle mass, cargo space, component packaging space, and total component count. Due to the thermal management challenges, the Department of Energy (DOE) supports research and development in thermal management of electric drive technologies through the Vehicle Technologies Program. The research includes the Energy Storage System (ESS) activity and the Advanced Power Electronics and Electric Machine (APEEM) activity.

Within the ESS and APEEM activities, the research goals are often tied to assumptions related to available coolant temperatures. The assumptions associated with coolant temperature have a dramatic impact on the research goals, the technical targets, and the ultimate direction of technology development. Determining the impact of the cooling system requires a higher level vehicle system view of how cooling systems are integrated into an overall vehicle thermal management strategy for alternative vehicle configurations that reduce fuel use. This work is an initial attempt to address the need by proposing a method to quantify the integrated heat loads of combined thermal management systems over a range of usage conditions. This paper also provides an initial overview of proposed methods for integrating the electric drive thermal management systems with other vehicle thermal management systems.

\section{REVIEW OF PRIOR WORK}

The traditional impact of vehicle thermal management systems on overall vehicle efficiency can be grouped into three general areas that include efforts to reduce thermal loads, transfer heat efficiently, and reuse available waste heat. Increasing the operating efficiency of components, transferring heat efficiently, or reducing the energy required for the vehicle thermal management system to function has been part of an active research task at the National Renewable Energy Laboratory (NREL) [2]. Specific actions include research into solarreflective glass, parked car ventilation, naturally ventilated seating, and active climate-control seating. Another example includes improving the efficiency of air conditioning systems by matching the performance to the need and thus avoiding reheat in conventional heating ventilation and air conditioning (HVAC) systems [2,3]. Also, the benefits of electronic control of accessory loads such as pumps and valves [4-8] in relation to improved component operating efficiency, improved control, or reduced parasitic power loads are gaining acceptance. These improvements apply to conventional and alternative propulsion technologies, as illustrated in the 2010 model year version of the Toyota Prius and the stated benefits related to the use of an electric water pump [9].

Vehicle thermal management technologies also enable energy efficiency improvements through reuse or waste heat utilization. Common examples include utilizing waste heat in the engine coolant for cabin heating and using waste heat in the exhaust for enabling emissions control devices. Waste heat from the exhaust can also improve engine warm-up to reduce fuel consumption and emissions through an exhaust heat recirculation system [9]. Significant effort through the years has also focused on recovering waste heat from exhaust and engine coolant to provide additional power using various waste heat recovery techniques. Examples include Rankine cycle heat recovery, turbocompounding, thermoelectric devices, and thermoacoustic waste heat recovery [2,10-14]. Waste heat utilization also includes storing waste heat for later use. For example, stored warm coolant was used to decrease warm-up time during cold starts $[15,16]$. Waste heat can also improve the

Page 2 of 15 
warm-up time of batteries [17] or improve transmission warm-up time and efficiency [18]. With the move toward more efficient vehicle propulsion technologies comes a reduction in waste heat. The reduced waste heat can have a negative impact on vehicle functions that require heat, such as cabin heating. Suggested technologies discussed in literature [3,4] include electric heaters, fuel fired heaters, heat pumps, exhaust gas heaters, and viscous shear heaters. Of the proposed technologies, heat pumps have received significant attention due to potential efficiency benefits by recovering heat from an external sink [19-23]. The application of these waste heat technologies depends on the vehicle propulsion configuration, the quantity of waste heat, and the quality of the waste heat.

\section{APPROACH}

Integrated vehicle thermal management can build on the above mentioned work to improve vehicle thermal management systems to reduce thermal loads, transfer heat efficiency, and reuse available waste heat. Integrated vehicle thermal management is not an add-on, a compartmentalized, or a component-focused thermal management strategy. Integrated vehicle thermal management reduces fuel use by enabling advanced vehicle technologies that reduce energy use directly or indirectly. Direct impacts include weight reduction and aerodynamic improvements due to component count reductions or size reductions. Indirect impacts include improvements in safety, part robustness, occupant comfort, and cost reduction, all leading to adoption of new technologies that reduce fuel use. All these actions support the development of advanced propulsion technologies to reduce fuel consumption.

The work described in this paper proposes techniques for quantifying the integrated heat loads of combined systems and applies the techniques to electric drive systems that experience their primary operation over transient duty cycles. The evaluation over transient thermal duty cycles is important because certain components may not experience peak thermal loads over steady-state tests typical of some conventional techniques for sizing thermal management systems. The approach consisted of three areas. The first task required the selection of representative vehicle configurations with similar performance characteristics to provide a fair comparison across multiple powertrain configurations. The selection of representative vehicle configurations enabled the comparison of heat loads across components and vehicle propulsion types. Second, the techniques for evaluating the transient and continuous heat loads were applied to the electric drive thermal management system. The results provided a method to investigate potential integration opportunities with other component thermal management systems. Finally, thermal and fluid system models were developed along with a heat exchanger sizing model for a louver fin heat exchanger to evaluate the viability of alternative concepts.

\section{VEHICLE CONFIGURATIONS}

Past work performed at NREL describing a previously published set of vehicle configurations provided a consistent set of vehicle configurations [24]. The paper describes four vehicle configurations including a conventional vehicle (CV), HEV, and two PHEV configurations. The hybrid configurations were based on a parallel hybrid configuration, as shown in Figure 1.

Simulated vehicle data over real-world or in-use conditions provided data for the heat load analysis. The transient duty cycles were required to stress the parallel configured electric drive components beyond what they would experience during a steady-state drive cycle up a grade at a fixed speed. The in-use drive cycles represented 227 vehicles from the St. Louis area where driving data was recorded with Global Positioning System (GPS) equipment. Converting the GPS data into second-by-second drive cycles over a 24-hour period provided representative drive cycles of actual vehicle use. The aggressiveness of the in-use drive cycles was

Page 3 of 15 
compared against standard light-duty vehicle test cycles in the NREL paper [24], and the aggressiveness exceeded common cycles such as the urban dynamometer driving schedule (UDDS) and US06 cycle.

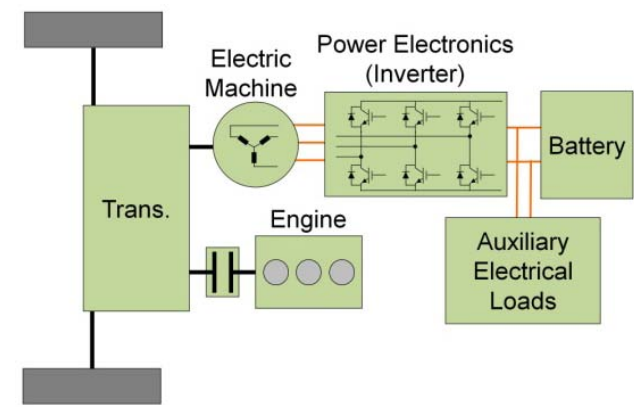

Figure 1: Parallel hybrid vehicle configuration.

The configured vehicles provided comparable acceleration and grade performance, and the PHEV20 and PHEV40 vehicles had the additional constraints related to all-electric range capability. The PHEV20 and PHEV40 vehicles had an all-electric range over the UDDS drive cycle of 20 and 40 miles, respectively. The component sizes in terms of peak power level are listed in Table A.1. Although not listed in Table A.1, estimates for an EV configuration were also included for comparison. The power flow through the EV electric drive system was calculated from the net power flow through the transmission inlet.

\section{HEAT LOAD ESTIMATION}

Approximate average component efficiency data enabled estimates for component and system heat loads. Table 1 lists the collected efficiency data for the key components. The actual efficiency depends on the operation of the components, but this level of detail was beyond the scope of the analysis. The values in Table 1 provided rough estimates for component efficiency. For example, the electric machine and power electronics efficiencies were based on knowledge that the electric drive system was not running at locations of peak efficiency, as shown in Figure 2 for the HEV configuration. The figure shows the operating location of the HEV over all 227 in-use drive cycles. The same could be shown for the PHEV with a slightly expanded area of operation. The operation is primarily at low torque where the electric drive is less efficient relative to the absolute peak efficiency. For example, one can compare to efficiency data recorded for electric drive systems in commercial HEV applications that show areas of higher peak operating efficiency $[15,25,26]$.

Table 1: Approximated output power and heat loads as percentage of input energy with approximated coolant temperatures.

\begin{tabular}{|l|l|l|l|l|}
\hline & Output Power [\%] & Coolant Waste Heat [\%] & Exhaust Waste Heat [\%] & Coolant Temperature [ $\left.{ }^{\circ} \mathrm{C}\right]$ \\
\hline ICE Engine & $25 \%[27-29]$ & $30 \%[27-29]$ & $40 \%[27-29]$ & $100[30,31]$ \\
\hline Power Electronics & $90 \%$ & $10 \%$ & NA & $65[32]$ \\
\hline Electric Machine & $90 \%$ & $10 \%$ & NA & $65[32]$ \\
\hline
\end{tabular}




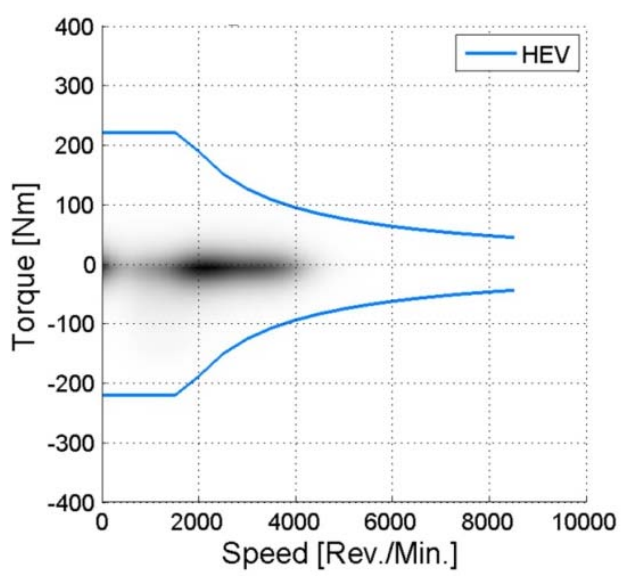

Figure 2: HEV PEEM operating time versus operating region (darker color represents more time) over 227 inuse drive cycles [33].

Using the efficiency data in Table 1, a method was developed to compare the transient and continuous heat loads from the 227 in-use drive cycles. The methodology resembles a procedure described by Markel and Pesaran [34] to calculate battery power averaged over expanding time windows. A similar process was also applied by the DOE Vehicle Technologies Program APEEM activity to look at PHEV impacts on electric drive systems [33]. The process of calculating the transient and continuous heat loads across all 227 in-use drive profiles involved computing a moving average (Equation 1) of a specified heat load versus time signal (x). The moving average sample size (n) was adjusted over a range of filter time windows $\left(\mathrm{t}_{\mathrm{w}}\right)$ using a fixed sample rate $\left(t_{s}\right)$. For the analysis the filter time windows ranged from 2 seconds to 200 seconds. In Equation 1 the parameter " $i$ " represents the data sample number, and " $k$ " is a counter based on the number of samples to include in the average.

$$
\begin{gathered}
y(i)=\frac{1}{n} \sum_{k=0}^{n-1} x(i-k), \\
n=\frac{t_{w}}{t_{s}},(2)
\end{gathered}
$$

The moving average heat load for a specified filter window size was computed over all 227 in-use drive cycle profiles, and the maximum value across all 227 drive cycles was stored to represent the peak heat load for the specified filter window size. The process was repeated over the full range of filter time windows and for each vehicle configuration. When plotted, the result is a vehicle configuration specific heat load curve showing the peak heat load over a range of transient and continuous operations. The technique was applied to individual systems and integrated systems involving the thermal management for the power electronics and electric machines.

\section{INTEGRATED THERMAL MANAGEMENT APPLICATIONS}

Current cooling systems for HEVs utilizing high power electric drive systems, such as the Toyota Prius, utilize a separate low temperature liquid cooling loop for cooling the power electronics and electric machines (Figure 3). The low temperature loop operates at a lower temperature than the ICE coolant loop, with a peak coolant temperature ranging from $65^{\circ} \mathrm{C}$ to $70^{\circ} \mathrm{C}[32,35]$. In comparison, the ICE liquid coolant loop operates at a higher

Page 5 of 15 
temperature, with radiator outlet temperatures assumed to be approximately $105^{\circ} \mathrm{C}$ [32]. However, the peak coolant temperature specifications out of the engine into a conventional radiator can approach $115^{\circ} \mathrm{C}$ to $120^{\circ} \mathrm{C}$ $[30,36]$. Figure 3 shows a general schematic of the thermal management systems for the heating ventilation and air conditioning system (HVAC), energy storage system (EES), ICE coolant loop, and the electric drive cooling system, which incorporates the power electronics and electric machine. One fact that stands out in the diagram is that the electric drive cooling system is a completely separate system while the other systems are integrated in some form.

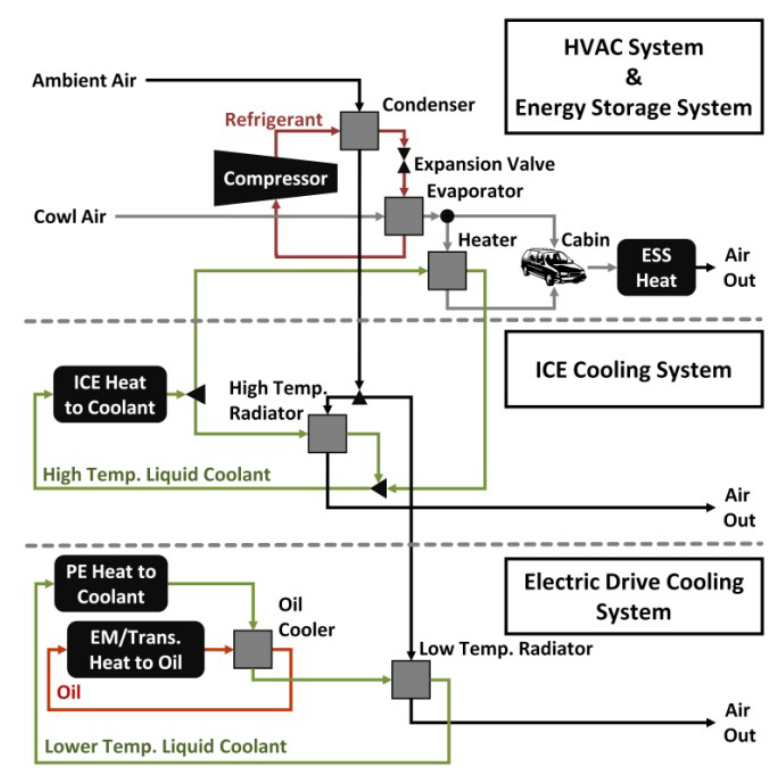

Figure 3: General schematic of the thermal management systems for HVAC, ESS, ICE, and electric drive systems (assumes the ESS is cooled with cabin air).

One research goal under the DOE Vehicle Technologies Program proposes one cooling loop for an HEV, allowing for a cost savings of approximately \$188 for an HEV such as the Toyota Prius [32]. This cost savings is significant when compared to cost targets of the APEEM activity within the DOE Vehicle Technologies Program [35]. For this reason, integrated thermal management of the electric drive system is a potential opportunity to reduce the cost of the power electronics and electric machine system. This paper describes two potential integration options for the electric drive system. The first integrates the electric drive thermal management system with the ICE coolant system, while the second integrates the electric drive system with the air conditioning system.

\section{HEAT EXCHANGER FEASIBILITY SIZING}

In addition to evaluating the impact of integrated heat loads, thermal and fluid system models were developed to investigate alternative arrangements of integrated thermal management systems within Aspen Plus and MATLAB. The models enabled analysis of performance impacts associated with heat loads, coolant flow rates, heat exchanger requirements, and ambient environmental conditions including temperature and humidity. The heat exchanger performance requirements were fed into a heat exchanger sizing model. The heat exchanger sizing analysis checked that the heat exchanger size could reasonably be packaged in a vehicle application that integrated the electric drive system and AC system. The assumptions associated with the heat exchanger analysis are described below, and additional details are found in existing literature by following the listed references.

Page 6 of 15 
The heat exchanger sizing model matched the required heat exchanger performance to the actual estimated performance based on the heat exchanger type, size, and operating conditions. The required heat exchanger performance (UA) based on the log mean temperature difference for a single-pass cross-flow heat exchanger with both fluids unmixed was calculated using the log mean temperature difference (LMTD) [37]. The required areas were calculated from given geometry ratios $[38,39]$ for calculating total air side area $\left(\mathrm{A}_{t}\right)$ from the heat exchanger frontal area $\left(\mathrm{A}_{\mathrm{fr}}\right)$. The geometry information for the selected louver fin geometry is listed in Table A.2. The heat exchanger width was fixed at $0.711 \mathrm{~m}(28 \mathrm{in}$.$) .$

The hot side convection coefficient was calculated assuming a rectangular tube with fully developed laminar flow [37]. The fluid properties were based on a $50 \%$ by mass mixture of water and ethylene glycol with fluid properties from [40] calculated at the mean fluid temperature. The tube height was calculated from the provided tube pitch $\left(\mathrm{T}_{\mathrm{p}}\right)$ and fin length $\left(\mathrm{F}_{1}\right)$ listed in Table A.2. The tube wall thickness was assumed to be $0.2 \mathrm{~mm}$. The Reynolds number was checked for each of the simulated conditions to verify laminar flow within the tube.

The air side heat transfer coefficient depended on the assumed air flow and heat exchanger construction. A louver fin geometry was selected based on published data and correlations $[38,39]$ that were also used by Shah [41]. In this analysis the air flow was set to maintain an $8^{\circ} \mathrm{C}$ temperature rise through the heat exchanger with an inlet air temperature of $40^{\circ} \mathrm{C}$. With the mass flow determined, the next step involved calculating the mass flux $(\mathrm{G})$ and maximum air velocity $\left(\mathrm{U}_{\max }\right)$ as defined in Kakac and Liu [42]. In order to prevent extreme values for the air mass flux through the heat exchanger, variable limits were included in the program to limit the mass flux to an upper limit $\left(\mathrm{G}_{\max }\right)$. If the air mass flux limit was exceeded, the heat exchanger area was increased. The correlations for estimating the air side heat transfer coefficient used a Reynolds number based on louver pitch at the inlet cold air density [38]. The number of heat exchanger rows or sections was increased until the required heat exchanger performance (UA) was met.

\section{RESULTS}

The results of the analysis approach focus on the key question related to integration opportunities for electric drive thermal management within a larger vehicle thermal management system context. The following results illustrate the challenges and opportunities for integrating the electric drive cooling system with either a high or low temperature vehicle thermal management system.

\section{HEAT LOAD ESTIMATION}

Figure 4 shows the heat load curves for the ICE and electric drive (PEEM) systems over multiple vehicle configurations for all 227 in-use drive cycles. The heat load curve graphs the heat load averaged or filtered over an expanding time duration or time window. For this reason the $\mathrm{x}$-axis is labeled "Filter Time Window". The heat load averaged over smaller time windows represents the transient heat load, while the heat load averaged over longer time windows provides an estimate for the continuous heat load. Figure 4a compares the relative heat load transferred to the ICE coolant for the simulated CV, HEV, and PHEV configurations. As expected, the peak or transient heat load is significantly higher in the CV application. The simplified efficiency assumptions use the same ICE efficiency for the CV, HEV, and PHEV configurations.

Figure $4 \mathrm{~b}$ compares the heat loads from the electric drive system or the combined power electronics and electric machine (PEEM) system. As expected, the heat load is significantly lower than the available heat in the ICE coolant. It is interesting to note the difference between the PHEV and HEV electric drive heat loads. As pointed out in previous work comparing HEV and PHEV operation for the DOE Vehicle Technologies Program APEEM activity, for a given PHEV energy management strategy, the impact on the electric drive system is Page 7 of 15 
primarily due to the transition from HEV to PHEV and not the transition from PHEV20 to PHEV40 [33]. The PHEV continuous heat load approaches the EV electric drive continuous power heat load over the in-use transient drive cycles, while the peak heat load depends on whether the PHEV is a blended configuration or an all-electric configuration. For an all-electric configuration, the peak heat load would be expected to match the approximated full EV electric drive peak heat load. Since this work was based on transient operating conditions, systems with more continuous operation of the electric drive system, such as electric vehicles or series configured hybrid electric vehicles, would require additional thermal analysis over conventional steady-state grade tests not covered in this paper. However, the approach can be easily expanded to include other drive cycles or tests.

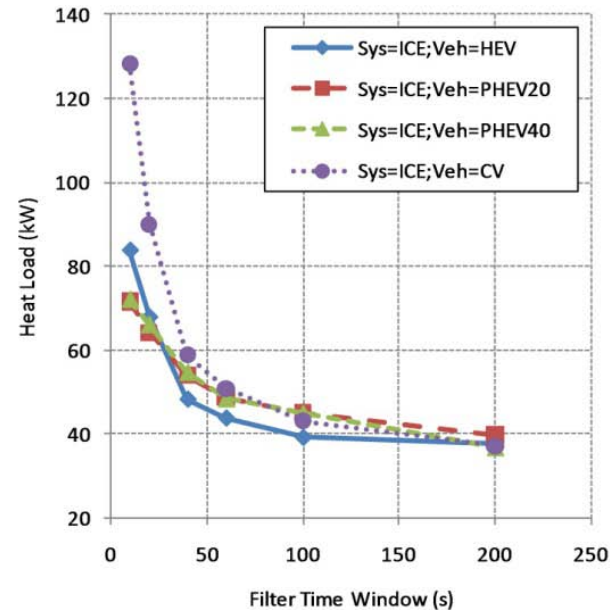

(a)

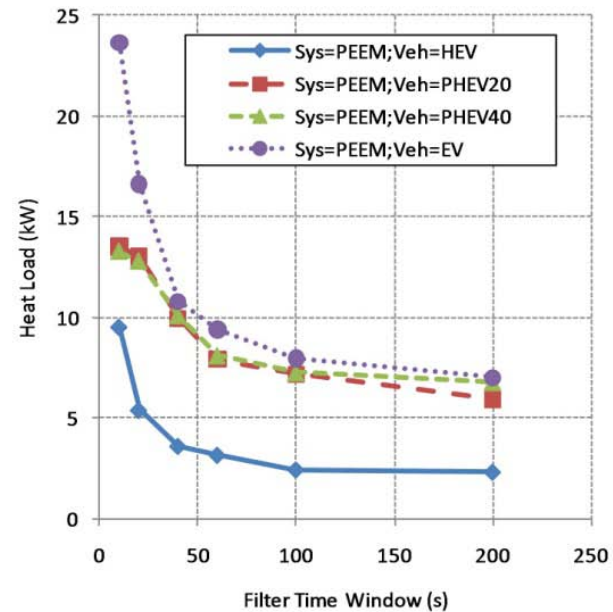

(b)

Figure 4: Heat load curves over 227 in-use drive cycles. (a) ICE coolant heat load curve averaged over variable time windows for HEV, PHEV20, PHEV40, and CV; (b) PEEM heat load curve averaged over variable time windows for HEV, PHEV20, PHEV40, and EV.

\section{INTEGRATED THERMAL MANAGEMENT APPLICATIONS}

There are two high level requirements for an integrated thermal management system. The first is a similar coolant temperature specification, and the second is a misalignment of peak heat loads of the combined or integrated systems. The heat load for integrated thermal management systems is not always simply the sum of the peak or continuous heat loads from the combined systems. Different components experience peak heat loads at different times depending on their use. Misalignment of the peak heat loads can potentially lead to an overall decrease in the net heat exchanger weight and volume. The ability of the heat load curve to illustrate both the transient and continuous heat loads was useful for evaluating the impact of combining multiple systems onto the same thermal management system where transient and continuous loading conditions are important. Two integration options for the PEEM cooling system were investigated, and the results related to temperature compatibility and heat load misalignment are described below.

\section{$\underline{\text { High Temperature Coolant ICE Integration }}$}

A single cooling loop based on the ICE thermal management system requires cooling the power electronics, electric machines, and internal combustion engine with one coolant. The power electronics inverter would thus have to tolerate inlet coolant temperatures up to $105^{\circ} \mathrm{C}$ [35]. When combining the ICE and electric drive coolant loops, the peak heat loads are not always added because the peak heat loads occur at different times depending

Page 8 of 15 
on the electric drive configuration and vehicle control strategy. An example is shown in Figure 5a with respect to the HEV parallel electric drive configuration.

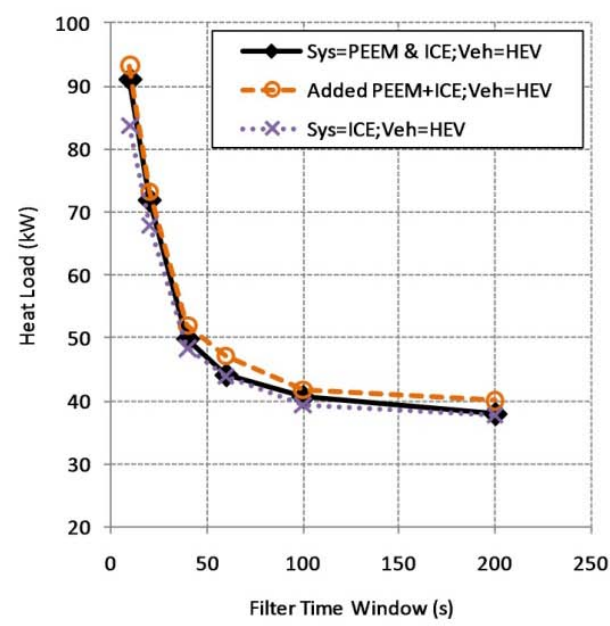

(a)

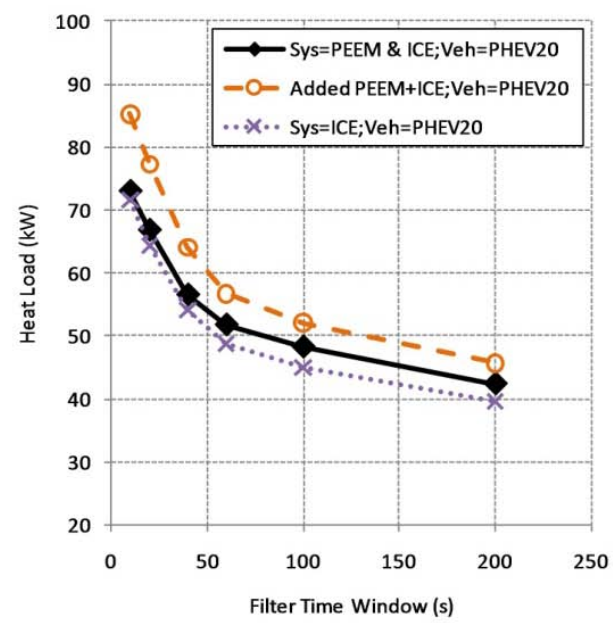

(b)

Figure 5: HEV heat load curves over 227 in-use drive cycles for the integrated PEEM and ICE system (solid line). The other curves compare the ICE heat load (dotted line) and the sum of the individual ICE and PEEM heat load curves (dashed line). (a) HEV; (b) PHEV20

Figure 5a compares three values. The first is the heat load in the ICE coolant shown by the dotted line (X marker). The second is the addition of the heat load curve of the ICE and the combined power electronics and electric machine (PEEM) heat load curve shown in Figure 4 for the HEV, which is illustrated by the dashed line (circle marker). Finally, the third solid curve (diamond marker) shows the integrated heat load by adding the heat loads in the time domain and generating the heat load curve using the combined heat loads versus time, which accounts for misalignment of peak heat loads. The curves in Figure 5a show that while the integrated system heat load is similar to the added heat load curve, it is not the same. Simply adding the curves assumed the peak heat loads were aligned and over-predicted the combined heat load. For transient conditions the two curves were similar, but the continuous heat load for the integrated system more closely resembled the heat load from the ICE alone. The reduced heat load highlighted an opportunity to integrate the two systems without a large increase in the continuous cooling capacity of the thermal management system relative to the ICE cooling system. The integration could reduce the costs associated with the separate electric drive coolant loop.

The PHEV configurations illustrated a more dramatic difference in the heat load curves. Figure $5 \mathrm{~b}$ shows the same information as Figure 5a except for the PHEV20 configuration. The PHEV20 showed a larger difference between integrated heat load (solid line with square markers) and added heat load curves (dashed line with circle markers). Although not shown, the same result was also found for the PHEV40 configuration. From the results for the simulated parallel PHEV configurations, the PHEV could be a better candidate for integrating the electric drive cooling system with the ICE cooling system.

While the integration of the electric drive thermal management system and ICE thermal management system was attractive for a PHEV in terms of the misalignment of peak heat loads, the second general requirement for similar coolant temperature specifications presented an issue. There are currently a number of challenges associated with cooling the power electronics and electric machine system with a high temperature coolant [32]. 


\section{$\underline{\text { Low Temperature Coolant AC Integration }}$}

The hurdles associated with using high temperature coolant for electric drive thermal management systems led to another option to integrate the low temperature liquid cooled electric drive system with other vehicle systems that could benefit from a low temperature liquid coolant. Ap et al. [36] proposed the use of a low temperature liquid coolant loop for the air conditioning (AC) condenser, charge air cooler, and fuel cooler, and mentioned that supplying $60^{\circ} \mathrm{C}$ coolant to the liquid-to-refrigerant condenser ensures adequate $\mathrm{AC}$ performance. The $60^{\circ} \mathrm{C}$ coolant temperature for the $\mathrm{AC}$ condenser is similar to the peak coolant temperatures for current production hybrid electric vehicles. For this reason, a proposal to integrate the low temperature coolant loop for the electric drive system with a liquid-to-refrigerant AC condenser was also investigated. The approach is shown generally in Figure 6. The general proposal of integrating the electric drive cooling with the AC system met the first basic requirement of similar coolant temperature specifications.

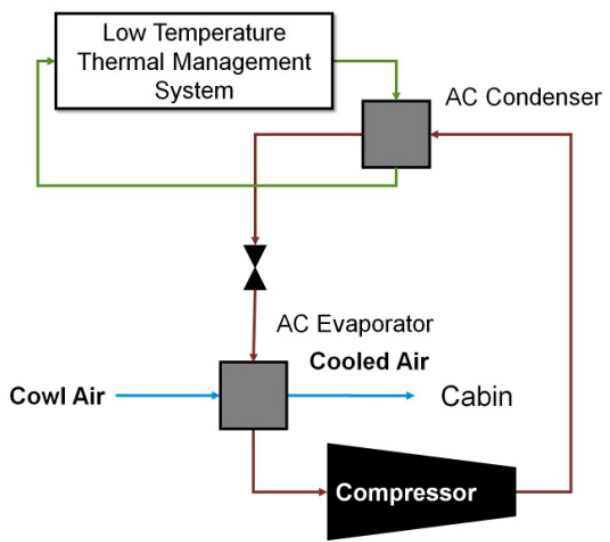

Figure 6: General schematic of electric drive and AC integrated thermal management system.

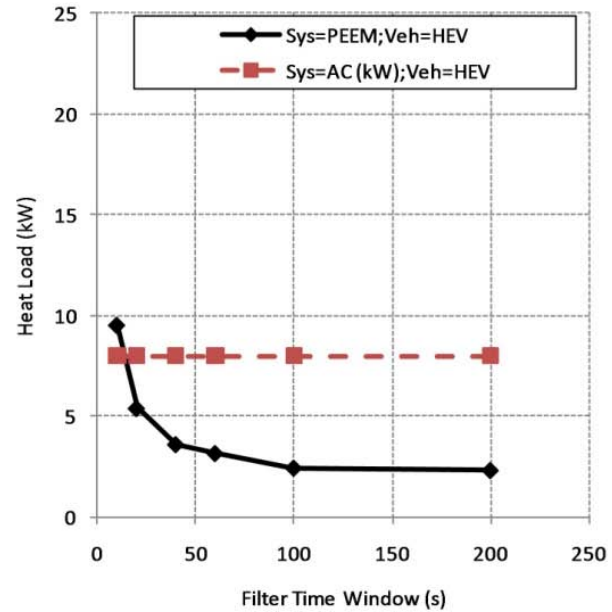

(a)

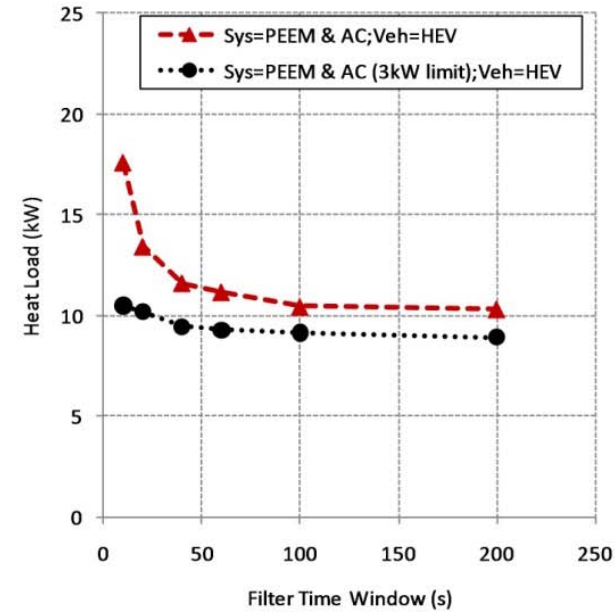

(b)

Figure 7: Heat load curves of combined PEEM and AC condenser systems over 227 in-use drive cycles. (a) PEEM heat load (diamond markers) and AC condenser heat load fixed at 8kW (square markers); (b) Combined PEEM and AC integrated heat load (triangle markers) and PEEM and AC integrated load with AC off when PEEM heat was over $3 \mathrm{~kW}$ (circle markers). 
The misalignment of the peak heat loads was also possible through control of the AC system operation and the lack of electric drive system heat when the vehicle was idle. The impact of controlling the AC system on the integrated heat load is shown in Figure 7. Figure 7a shows the system specific heat load curves for the combined power electronics and electric machine (PEEM) components and the AC condenser heat load, which was fixed at $8 \mathrm{~kW}$. Integrating the PEEM and $\mathrm{AC}$ condenser heat loads with the AC always on resulted in the combined heat load curve shown in Figure $7 \mathrm{~b}$ with the dashed line (triangle markers). The impact of turning off the AC during brief periods when the PEEM heat load exceeded $3 \mathrm{~kW}$ is shown in Figure $7 \mathrm{~b}$ with the dotted line (circle markers). Controlling the AC system to turn off during transient high power operation of the electric drive or PEEM system produced a significant transient and continuous heat load reduction for the combined or integrated system.

\section{$\underline{\text { Heat Exchanger Feasibility Sizing }}$}

A thermal system model was developed to look at opportunities to integrate the AC condenser with the low temperature cooling system, including models of the two-phase air conditioning system, single-phase low temperature coolant loop, ambient air inlet, and the necessary heat exchangers. The electric drive system was incorporated into the model as a heat load into the coolant system. The concept applies to any electric drive system with a vehicle air conditioning system. The key advantage includes multiple uses of the low temperature loop, which enables a lower temperature coolant for power electronics. The system could replace the air to refrigerant condenser at the front of the vehicle with a liquid to refrigerant condenser that can be packaged with the HVAC system. In addition, other potential benefits relate to reduced refrigerant lines, leaks, and pressure drops. The viability of the integrated thermal management concept required feasibility analysis for the size of the low temperature heat exchanger.

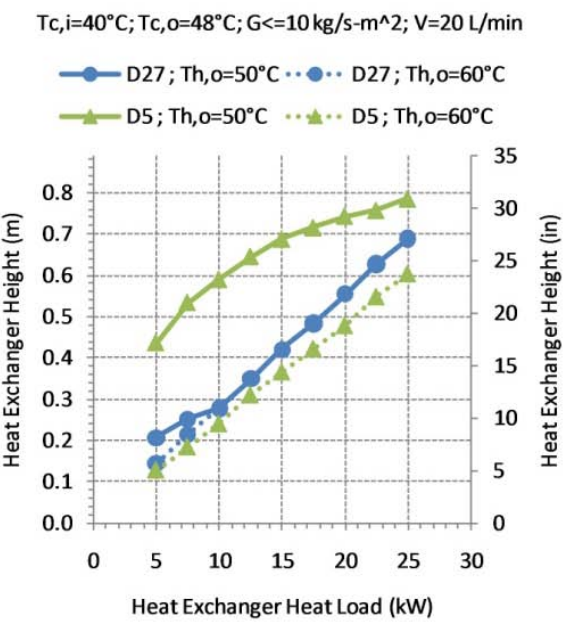

(a)

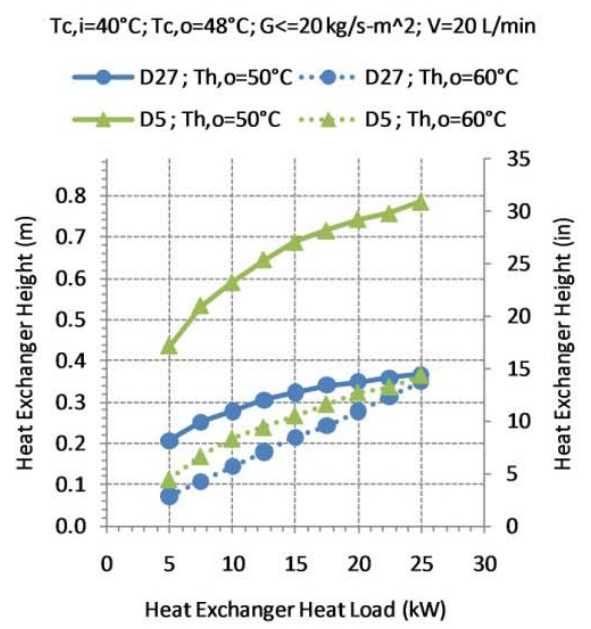

(b)

Figure 8: Louver fin heat exchanger height vs. heat load for a fixed $0.711 \mathrm{~m} \mathrm{(28} \mathrm{in.)} \mathrm{width;} \mathrm{(a)} \mathrm{G}_{\max }=10 \mathrm{~kg} / \mathrm{s}-\mathrm{m}^{2}$ and $\mathrm{V}_{\mathrm{h}}=20 \mathrm{~L} / \mathrm{min}$; (b) $\mathrm{G}_{\max }=20 \mathrm{~kg} / \mathrm{s}-\mathrm{m}^{2}$ and $\mathrm{V}_{\mathrm{h}}=20 \mathrm{~L} / \mathrm{min}$.

A preliminary analysis of the low temperature heat exchanger was performed following the previously described approach. The results are shown in Figure 8 for an air inlet temperature $\left(\mathrm{T}_{\mathrm{c}, \mathrm{i}}\right)$ of $40^{\circ} \mathrm{C}$ and air outlet temperature $\left(\mathrm{T}_{\mathrm{c}, \mathrm{o}}\right)$ of $48^{\circ} \mathrm{C}$. Figure 8 compares the two heat exchanger geometries (D5 and D27) [38,39] for different operating requirements in terms of the maximum allowable air mass flux $\left(\mathrm{G}_{\max }\right)$, water ethylene glycol volumetric flow rate $\left(\mathrm{V}_{\mathrm{h}}\right)$, and water ethylene glycol outlet temperature $\left(\mathrm{T}_{\mathrm{h}, \mathrm{o}}\right)$. Figure 8a shows that except for the D5 heat exchanger at a $\mathrm{T}_{\mathrm{h}, \mathrm{o}}$ of $50^{\circ} \mathrm{C}$, the size or height of the heat exchanger was determined by the

Page 11 of 15 
limitation placed on the maximum air mass flux, which is seen in the linear portions of the curves. Figure $8 \mathrm{~b}$ shows that if the air mass flux limit is increased, the size of the heat exchanger is reduced in most situations except for D5. The size of the D27 heat exchanger at a $\mathrm{T}_{\mathrm{h}, \mathrm{o}}$ of $60^{\circ} \mathrm{C}$ was still limited by the air mass flux limit as seen in the linear shape of the curve. In each of the conditions the size of the heat exchanger appeared to be reasonable except for the D5 heat exchanger at higher heat loads. Although not shown, the analysis was also repeated at different coolant flow rates with similar results.

\section{SUMMARY/CONCLUSIONS}

The proposed method of using the generated heat load curve provided a method for evaluating the transient and continuous heat loads of individual components and integrated thermal management systems over actual in-use conditions for components that experience significant transient use. The developed techniques can easily be expanded to include other vehicle drive cycles or test conditions that include both transient and continuous operation, and the analysis can be expanded to include additional components or more detailed heat load estimates. The techniques were applied to the electric drive thermal management system to investigate potential integration opportunities with the ICE and AC thermal management systems. The high temperature thermal management system, integrating the electric drive and ICE systems, showed a potential application especially for PHEV configurations. However, the high temperature is an issue for current commercial electric drive systems. The low temperature thermal management system integrated the electric drive system with the vehicle air conditioning system. The system showed similar operating temperature requirements and a potential synergy in the heat duty cycle versus time depending on the control of the AC system.

The integration of the low temperature power electronics and electric machine thermal management system with other vehicle systems takes the work by Ap et al. [36] a step further to investigate integration opportunities related to alternative vehicle propulsion technologies. Specifically, applications include propulsion systems with electric drive systems such as HEVs, PHEVs, FCVs, and EVs. A liquid cooled AC condenser improves front end packaging, reduces refrigerant lines, and increases AC condenser package flexibility [36]. In addition to the benefits outlined by Ap et al. [36], there are additional potential benefits related to the integration of the AC and electric drive systems utilizing a low temperature liquid coolant. The additional benefits would apply not only to the $\mathrm{AC}$ system but also to the electric drive system. The AC system benefits through the integration of the AC condenser into a sealed HVAC system. Developing a sealed system could eliminate or reduce refrigerant leaks and the need to refill the AC refrigerant lines, leading to improved AC robustness. Locating the AC condenser close to the HVAC system would also reduce the length of the refrigerant lines, leading to a lower pressure drop through the system. The reduced pressure drop improves the AC operating efficiency. The electric drive system benefits by sharing the cost of the low temperature coolant loop. The system also enables forms of power electronics and electric machine temperature protection without reducing the electric drive performance.

System thermal and fluid models and heat exchanger sizing models show the potential of integrating the power electronics and electric machine cooling with the air conditioning system. While there appear to be synergies related to temperature and heat loading, a more thorough analysis of an implementable concept is required. The next step in the analysis appears justifiable based on the potential viability and benefits of the system.

\section{REFERENCES}

1. Fulton, W., Giesler, J., and Patton, H., "Cooling System for Internal Combustion Engines," U.S. Patent 1,306,000, June 10, 1919.

Page 12 of 15 
2. Rugh, J., "Vehicle Ancillary Load Reduction Close-Out Report," National Renewable Energy Laboratory Report, NREL/TP-540-42454, January 2008.

3. Eilemann, A. and Kampf, H., "Comfort-Management," SAE 2001-01-1738, 2001.

4. Chalgren, R., "Thermal Comfort and Engine Warm-Up Optimization of a Low-Flow Advanced Thermal Management System," SAE 2004-01-0047, 2004.

5. Chanfreau, M. and Farkh, A., "The Need for an Electrical Water Valve in a Thermal Management Intelligent System (ThemisSt)," SAE 2003-01-0274, 2003.

6. Jawad, B., Zellner, K., and Riedel, C., "Small Engine Cooling and the Electric Water Pump," SAE 2004-320084, 2004.

7. Wagner, J., Srinivasan, V., Dawson, D., and Marotta, E., "Smart Thermostat and Coolant Pump Control for Engine Thermal Management Systems," SAE 2003-01-0272, 2003.

8. Wagner, J., Ghone, M., Dawson, D., and Marotta, E., "Coolant Flow Control Strategies for Automotive Thermal Management Systems," SAE 2002-01-0713, 2007.

9. Kawamoto, N., Naiki, K., Kawai, T., Shikida, T. and Tomatsuri, M., "Development of New 1.8-Liter Engine for Hybrid Vehicles," SAE 2009-01-1061, 2009.

10. Brands, M., Werner, J., Hoehne, J., and Kramer, S., "Vehicle Testing of Cummins Turbocompund Diesel Engine," SAE 810073, 1981.

11. Doyle, E., DiNanno, L., and Kramer, S., "Installation of a Diesel-Organic Rankine Compound Engine in a Class 8 Truck for a Single-Vehicle Test," SAE 790646, 1979.

12. Foster, D. and Myers, P., "Heavy-Duty Diesel Fuel Economy," ASME Mechanical Engineering, 104(12):50-55, Dec. 1982.

13. Oomori, H. and Ogino, S., "Waste Heat Recovery of Passenger Car Using a Combination of Rankine Bottoming Cycle and Evaporative Engine Cooling System," SAE 930880, 1993.

14. Smith, K. and Thornton, M., "Feasibility of Thermoelectrics for Waste Heat Recovery in Hybrid Electric Vehicles," presented at EVS-23, Anaheim, CA, USA, Dec. 2-5, 2007.

15. Staunton, R., Ayers, C., Marlino, L., Chiasson, C., and Burress, T., "Evaluation of 2004 Toyota Prius Hybrid Electric Drive System," Oak Ridge National Laboratory Technical Report, ORNL/TM-2006/423, 2006.

16. Muta, K., Yamazaki, M., and Tokieda, J., "Development of New-Generation Hybrid System THS II Drastic Improvement of Power Performance and Fuel Economy," SAE 2004-01-0064, 2004.

17. Pesaran, A., Vlahinos, A., and Stuart, T., "Cooling and Preheating of Batteries in Hybrid Electric Vehicles," presented at 6th ASMR-JSME Thermal Engineering Conference, Hawaii, USA, Mar. 16-20, 2003.

18. Semel, R., "Fuel Economy Improvements through Improved Automatic Transmission Warm-up - Stand Alone Oil To Air (OTA) Transmission Cooling Strategy with Thermostatic Cold Flow Bypass Valve," SAE 2001-01-1760, 2001.

19. Ghodbane, M., Scherer, L., Baker, J., and Kadle, P., "Potential applications of R-152a refrigerant in vehicle climate control," 2003 Vehicle Thermal Management Systems Conference (VTMS6), IMechE C599/083/2003, May 2003.

20.Pomme, V., "Reversible Heat Pump System for and Electric Vehicle," SAE 971772, 1997.

21. Scherer, L., Ghodbane, M., Baker, J., and Kadle, P., "On-Vehicle Performance Comparison of an R-152a and R-134a Heat Pump System," SAE 2003-01-0733, 2003.

22. Vetter, F. and Memory, S., "Automotive AC/HP Systems using R744(CO2)," 2003 Vehicle Thermal Management Systems Conference (VTMS6), IMechE C599/098/2003, May 2003.

23.Zeng, X., Major, G., Hirao, T., and Imaiida, T., “An Automotive Hybrid Heating System for Parallel Hybrid Passenger Cars," SAE 2000-01-1276, 2000.

Page 13 of 15 
24. Gonder, J., Markel, T., Simpson, A., and Thornton, M., "Using GPS Travel Data to Assess the Real World Driving Energy Use of Plug-In Hybrid Electric Vehicles (PHEVs)," presented at the Transportation Research Board (TRB) 86th Annual Meeting, Washington, D.C., USA, Jan. 21-25, 2007.

25. Burress, T., Coomer, C., Campbell, S., Seiber, L., Marlino, L., Staunton, R., and Cunningham, J., "Evaluation of the 2007 Toyota Camry Hybrid Synergy Drive System," Oak Ridge National Laboratory Technical Report, ORNL/TM-2007/190, 2008.

26. Burress, T., Coomer, C., Campbell, S., Wereszczak, A., Cunningham, J., Marlino, L., Seiber, L., and Lin, H., "Evaluation of the 2008 Lexus LS 600H Hybrid Synergy Drive System," Oak Ridge National Laboratory Technical Report, ORNL/TM-2008/185, 2009.

27. Chammas, R. and Clodic, D., "Combined Cycle for Hybrid Vehicles," SAE 2005-01-1171, 2005.

28. Heywood, J., Internal Combustion Engine Fundamentals. McGraw-Hill, New York, 1988.

29. Stobart, R. and Weerasinghe, R., "Heat Recovery and Bottoming Cycles for SI and CI Engines - A Perspective," SAE 2006-01-0662, 2006.

30. Automotive Handbook, 4th ed., Robert Bosch GmbH, Germany, 1996.

31. Hughes, C., and Wiseman, M., "Feasibility of Intelligent Control Strategies to Reduce Cooling System Size," SAE 2001-01-1759, 2001.

32. Hsu, J., Staunton, R., and Starke, M., "Barriers to the Application of High-Temperature Coolants in Hybrid Electric Vehicles," Oak Ridge National Laboratory Technical Report, ORNL/TM-2006/514, 2006.

33. Bennion, K., "Plug-In Hybrid Electric Vehicle Impacts on Power Electronics and Electric Machines," National Renewable Energy Laboratory Report, NREL/MP-540-36085, September 2007.

34. Markel, T. and Pesaran, A., "PHEV Energy Storage and Drive Cycle Impacts," presented at the 7th Advanced Automotive Battery Conference, Long Beach, California, May 2007.

35. FreedomCAR and Fuels Partnership. "Electrical and Electronics Technical Team Roadmap," http:/www.eere.energy.gov/vehiclesandfuels/pdfs/program/eett roadmap.pdf, November 2006.

36. Ap, N-S., Guerrero, P., Jouanny, P., Potier, M., Genoist, J., and Thuez, J., "UltimateCooling ${ }^{\mathrm{TM}} \mathrm{New}$ Cooling System Concept Using the Same Coolant to Cool All Vehicle Fluids," 2003 Vehicle Thermal Management Systems Conference (VTMS6), IMechE C599/010/2003, May 2003.

37. Incropera, F. and DeWitt, D., Fundamentals of Heat and Mass Transfer, 4th ed., John Wiley \& Sons, New York, 1996.

38. Davenport, C., "Correlations for Heat Transfer and Flow Friction Characteristics of Louvred Fin," Proceedings of the 21st National Heat Transfer Conference, AIChE Symposium Series, 225:19-27, 1983.

39. Park, Y. and Jacobi, A., "Air-Side Heat Transfer and Friction Correlations for Flat-Tube Louver-Fin Heat Exchangers," Journal of Heat Transfer 131, Feb. 2009.

40. Alshamani, K., "Equations for Physical Properties of Automotive Coolants," SAE 2003-01-0532, 2003.

41. Shah, R., Kraus, A., and Metzger, D., Compact Heat Exchangers, Hemisphere Publishing, New York, 1990.

42. Kakac, S. and Liu, H., Heat Exchangers Selection, Rating, and Thermal Design, CRC Press, New York, 1998.

\section{CONTACT INFORMATION}

Kevin.Bennion@nrel.gov

\section{ACKNOWLEDGMENTS}

The authors would like to acknowledge Lee Slezak and the programmatic support of the Vehicle Technologies Program in the U.S. Department of Energy's Office of Energy Efficiency and Renewable Energy.

Page 14 of 15 


\section{APPENDIX}

Table A.1: Vehicle component power ratings [24].

\begin{tabular}{|l|l|l|l|}
\hline & ICE Output Power [kW] & EM Output Power [kW] & ESS Output Power [kW] \\
\hline CV & 122 & NA & NA \\
\hline HEV & 82 & 39 & 50 \\
\hline PHEV 20 & 79 & $44(50)^{* *}$ & 47 \\
\hline PHEV40 & 82 & $48(50)^{* *}$ & 52 \\
\hline
\end{tabular}

** Listed electric machine (EM) power is the necessary power for all electric operation over the UDDS cycle. A $50 \mathrm{~kW}$ machine was used for the PHEV configuration simulations.

Table A.2: Louver fin heat exchanger geometry $[38,39]$.

\begin{tabular}{|l|l|l|l|l|l|l|l|l|l|}
\hline$\#$ & $\mathrm{~L}_{\mathrm{p}}(\mathrm{mm})$ & $\mathrm{L}_{\mathrm{h}}(\mathrm{mm})$ & $\mathrm{L}_{1}(\mathrm{~mm})$ & $\mathrm{F}_{1}(\mathrm{~mm})$ & $\mathrm{T}_{\mathrm{p}}(\mathrm{mm})$ & $\mathrm{D}_{\mathrm{h}, \mathrm{c}}(\mathrm{mm})$ & $\mathrm{A}_{\mathrm{c}} / \mathrm{A}_{\mathrm{fr}}$ & $\mathrm{A}_{\mathrm{t}} / \mathrm{A}_{\mathrm{fr}}$ & $\delta_{f}(\mathrm{~mm})$ \\
\hline Source & {$[38,39]$} & {$[38]$} & {$[38,39]$} & {$[39]$} & {$[39]$} & {$[38]$} & {$[38]$} & {$[38]$} \\
\hline D5 & 2.25 & 0.31 & 9.5 & 12.7 & 14 & 2.8 & 0.816 & 49.88 & 0.075 \\
\hline D27 & 2.25 & 031 & 7.1 & 7.8 & 8.93 & 2.14 & 0.738 & 60.25 \\
\hline
\end{tabular}

See variable definitions listed below.

\section{$A_{c}$ : Minimum cross-sectional area for air flow}

$A_{\text {fr }}$ : Frontal area of heat exchanger

$A_{t}$ : Total air side heat exchanger area

$D_{h, c}:$ Hydraulic diameter for air passage

$\mathrm{F}_{1}$ : Fin length

$L_{h}$ : Louver height

$\mathrm{L}_{\mathrm{l}}$ : Louver length

$L_{p}$ : Louver pitch

$T_{p}$ : Tube pitch

$\delta_{\mathrm{f}}:$ Fin thickness 


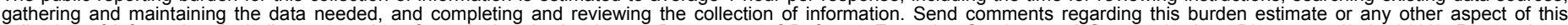

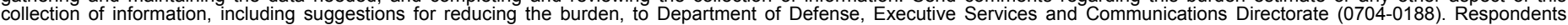

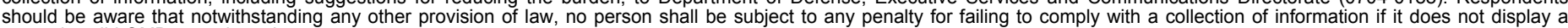

chould be aware that notwithstanding

PLEASE DO NOT RETURN YOUR FORM TO THE ABOVE ORGANIZATION.

February 2010

Conference Paper

4. TITLE AND SUBTITLE
Integrated Vehicle Thermal Management for Advanced Vehicle

Propulsion Technologies: Preprint

5a. CONTRACT NUMBER

DE-AC36-08-GO28308

5b. GRANT NUMBER

5c. PROGRAM ELEMENT NUMBER

6. AUTHOR(S)

K. Bennion and M. Thornton 5d. PROJECT NUMBER

NREL/CP-540-47416

5e. TASK NUMBER

FC102300

5f. WORK UNIT NUMBER
7. PERFORMING ORGANIZATION NAME(S) AND ADDRESS(ES)

National Renewable Energy Laboratory

1617 Cole Blvd.

Golden, CO 80401-3393

9. SPONSORING/MONITORING AGENCY NAME(S) AND ADDRESS(ES)
8. PERFORMING ORGANIZATION

REPORT NUMBER

NREL/CP-540-47416

10. SPONSOR/MONITOR'S ACRONYM(S) NREL

11. SPONSORING/MONITORING AGENCY REPORT NUMBER

\section{DISTRIBUTION AVAILABILITY STATEMENT}

National Technical Information Service

U.S. Department of Commerce

5285 Port Royal Road

Springfield, VA 22161

\section{SUPPLEMENTARY NOTES}

14. ABSTRACT (Maximum 200 Words)

As vehicle propulsion transitions away from a single form of vehicle propulsion based solely on conventional internal combustion engines (ICEs) toward a wider array of choices including more electrically dominant systems such as plug-in hybrid electric vehicles (PHEVs), new challenges arise associated with vehicle thermal management. As the number of components that require active thermal management increase, so do the costs in terms of dollars, weight, and size. Integrated vehicle thermal management is one pathway to address the cost, weight, and size challenges. The integration of the power electronics and electric machine (PEEM) thermal management with other existing vehicle systems is one path for reducing the cost of electric drive systems. This work demonstrates techniques for evaluating and quantifying the integrated transient and continuous heat loads of combined systems incorporating electric drive systems that operate primarily under transient duty cycles, but the approach can be extended to include additional steady-state duty cycles typical for designing vehicle thermal management systems of conventional vehicles. The work compares opportunities to create an integrated low temperature coolant loop combining the power electronics and electric machine with the air conditioning system in contrast to a high temperature system integrated with the ICE cooling system.

15. SUBJECT TERMS

"plug-in hybrid electric vehicles" ; "PHEV" ; "thermal management" ; "PEEM" ; "heat loads"

\begin{tabular}{|c|c|c|}
\hline \multicolumn{3}{|c|}{ 16. SECURITY CLASSIFICATION OF: } \\
\hline $\begin{array}{l}\text { a. REPORT } \\
\text { Unclassified }\end{array}$ & $\begin{array}{l}\text { b. ABSTRACT } \\
\text { Unclassified }\end{array}$ & $\begin{array}{l}\text { c. THIS PAGE } \\
\text { Unclassified }\end{array}$ \\
\hline
\end{tabular}

\begin{tabular}{l|l} 
17. LIMITATION & 18. \\
OF ABSTRACT \\
OF PAGES \\
UL
\end{tabular}

19a. NAME OF RESPONSIBLE PERSON

19b. TELEPHONE NUMBER (Include area code) 